\title{
First results of all-sky imaging from India
}

\author{
G. K. Mukherjee, L. Carlo, S. H. Mahajan, and P. T. Patil
}

Indian Institute of Geomagnetism, Colaba, Mumbai 400 005, India

(Received December 12, 1995; Revised September 14, 1997; Accepted September 22, 1997)

\begin{abstract}
A CCD based all-sky ( $180^{\circ}$ field view) airglow imaging system was operated from a low latitude station, Kolhapur $\left(16.8^{\circ} \mathrm{N}, 74.2^{\circ} \mathrm{E} ; 10.6^{\circ} \mathrm{N}\right.$ dip lat.) in India to map the thermospheric motion and to study the low latitude ionospheric irregularities by measuring the nightglow signatures at $630 \mathrm{~nm}$. In general, all-sky imaging techniques offer broad, instantaneous coverage $\left(2.5\right.$ million sq $\mathrm{km}$ area at $150^{\circ}$ field of view at $300 \mathrm{~km}$ height $)$ of the spatial and temporal characteristics of the airglow features from the selected layers of the thermosphere and ionosphere system. In addition to the all-sky camera, photometer and radio scintillation observations together with ionospheric soundings were carried out from Kolhapur to verify the signature of small scale as well as large scale size $F$-region irregularities. Initial results from these measurements display good examples of north-south motion of the thermosphere with apparent drift speeds of 143-200 m/s during geomagnetically quiet nights. The north-south aligned $(>1000 \mathrm{~km})$ bands of plasma depletions or bubbles with east-west dimension of $50-250 \mathrm{~km}$ moving with drift speed of $140 \mathrm{~m} / \mathrm{s}$ towards east have been observed. The zonal component of plasma drift speed matches well with the eastward component of the neutral speed computed using Hedin's recent model. However, the meridional components of plasma drift speed are generally higher than the components of the neutral wind speed computed using the model. The results confirm the earlier quantitative investigations of equatorial depletion characteristics from Brazil and elsewhere.
\end{abstract}

\section{Introduction}

Equatorial bubbles as well as small scale size ionospheric irregularities have been extensively studied in the last two decades by using incoherent back scatter radar, rockets, satellites and UHF/VHF scintillation measurements (Weber et al., 1978, 1980, 1982, 1983; Mendillo and Baumgardner, 1982; Sobral et al., 1985). It is generally believed that the bubbles (depletions) are generated in the bottomside of the equatorial $F$-region after sunset and they move buoyantly upward with respect to ambient plasma in the equatorial ionosphere due to Rayleigh Taylor or $\boldsymbol{g} \times \boldsymbol{B}$ instability (Woodman and La Hoz, 1976; Fejer et al., 1981; Zalesak and Ossakow, 1982; Anderson and Mendillo, 1983; Mendillo et al., 1992; Sinha et al., 1996). They are generally aligned along the geomagnetic field lines due to their much greater conductivity in the magnetic field direction than perpendicular to it. Within these bubbles, small as well as large scale size ionospheric irregularities from 1 metre to tens of kilometres, give rise to VHF backscatter, VHF and UHF scintillations and Equatorial Spread- $F$ (ESF). At the boundaries of these depletions, smaller size irregularities are generally produced. The optical imaging techniques (Weber et al., 1978, 1980; Mendillo and Baumgardner, 1982; Tinsley, 1982; Mendillo and Tyler, 1983, Mukherjee et al., $1993,1994)$ from $10^{\circ}$ to $15^{\circ}$ dip latitude regions can very well provide information about structure of these plasma depletions above the magnetic equator as well as their temporal movement in east-west direction which can be

Copy right (C) The Society of Geomagnetism and Earth, Planetary and Space Sciences (SGEPSS); The Seismological Society of Japan; The Volcanological Society of Japan; The Geodetic Society of Japan; The Japanese Society for Planetary Sciences. compared with other experimental techniques. Monochromatic imaging of the large scale $F$-region plasma depletions that contain the equatorial bubbles and associated ionospheric irregularities typically manifest themselves as regions of low $630 \mathrm{~nm}$ emission. Weber et al. (1978, 1980, 1983), Mendillo and Baumgardner (1982) and Muldrew (1980) through their pioneering work, studied the characteristics of equatorial ionospheric plasma depletions using all-sky camera at $630 \mathrm{~nm}$. They found out north-south aligned structures often more than $1200 \mathrm{~km}$ in length with east-west dimensions of 50-200 km. The depletions appeared after sunset and were observed to move towards east with speeds of $50-150 \mathrm{~m} / \mathrm{s}$. While drifting, the feet of these structures migrate towards the poles reaching \pm 15 dip latitudes (McClure et al., 1977, Rohrbaugh et al., 1989; Sahai et al., 1994). Topside ionosonde measurement (Dyson and Benson, 1978) showed their propagation characteristics which are mainly aligned along geomagnetic field lines. With a view to examine the relation of airglow depletions to amplitude scintillations on trans-ionospheric communication links, the movement of airglow depletions through the signal ray path produced intense amplitude (VHF and UHF) scintillations (often $>20 \mathrm{~dB}$ at $250 \mathrm{~Hz}$ ) implying existence of $0.5-$ $10 \mathrm{~km}$ scale size irregularities (Weber et al., 1980, 1983) within the depletions. Though there are a good number of experimental observations of plasma depletions or bubbles showing their spatial and temporal characteristics from the American longitude sector and other regions (Hake, 1981; Sahai et al., 1981, 1994, 1996; Carman, 1983; Malcolm et al., 1984; Rohrbaugh et al., 1989; Fukunishi, 1996; and references therein) in the last two decades, these results are not supported by similar characteristic observations from 
the Indian longitude region. This is mainly due to the lack of a suitable imaging system operating in this sector. Recently a CCD based all-sky imaging system has been installed at Kolhapur $\left(16.8^{\circ} \mathrm{N}, 74.2^{\circ} \mathrm{E}\right)$ to map the thermospheric motions by studying various nightglow emissions.

In this report we describe a new series of optical measurements from a low latitude station, Kolhapur in India, using a ground based all-sky imaging system. These are the first series of optical measurements with a CCD based allsky camera from Indian low latitude region. Simultaneously, the limited data set from other complementary experiments such as radio beacon scintillation, ionosonde and photometers are also examined to study small as well as large scale size irregularities.

\section{All-Sky Camera}

A CCD based all-sky imaging system ( $180^{\circ}$ field of view) was operated from Kolhapur. The salient features of the design of the CCD based imaging system have been explained by Baumgardner and Karandanis (1984) and Mendillo et al. (1989). The fisheye lens (16 mm, f/2.8) at the top of the camera takes in light in $2 \pi$ steradians from the sky. The function of the $40 \mathrm{~mm}$ diameter field lens and the $300 \mathrm{~mm}$ $\mathrm{f} / 2.5$ Aero Ektar lens is to collimate the light from the sky. The fisheye lens produces a circular image of the sky $23 \mathrm{~mm}$ in diameter which is directed in to the collimator (Fig. 1). Finally the light after passing through the filter is reimaged at $f / 1$ onto the photocathode of the intensified CCD of Fairchild Model 3000 and intensifier type 4727 of ITT. The

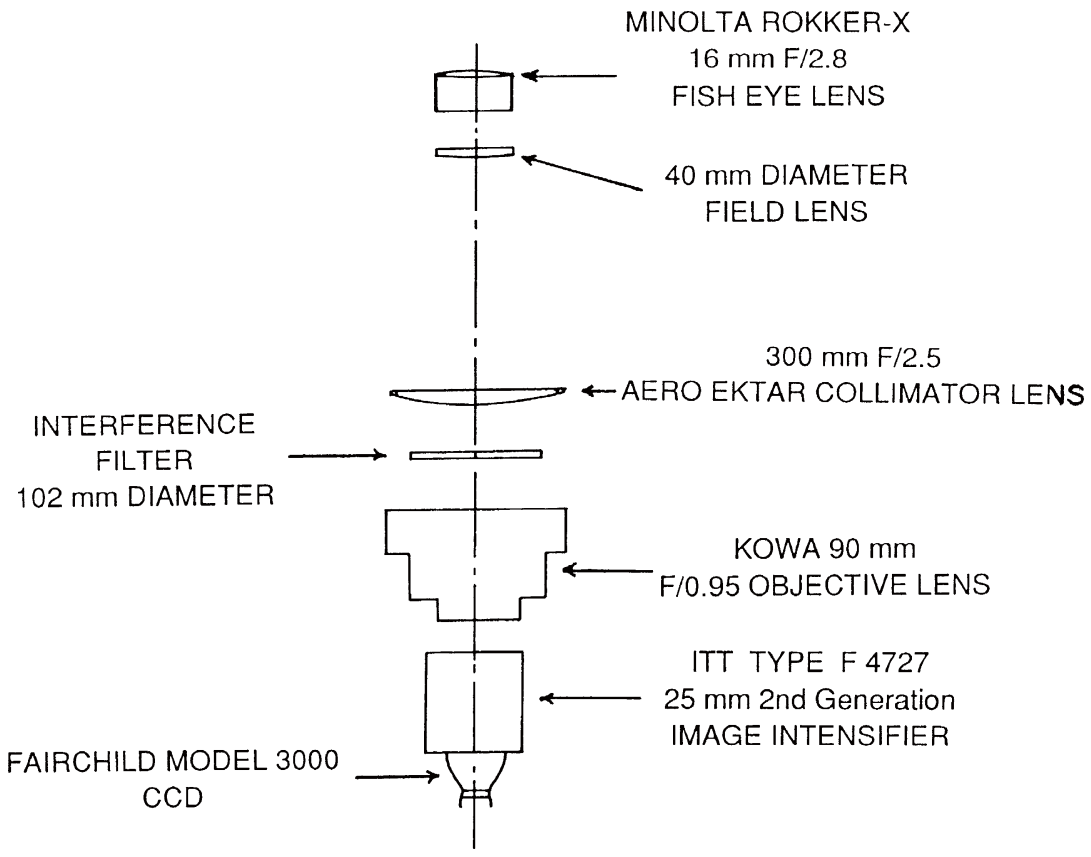

Fig. 1. Schematic diagram of the all-sky camera.

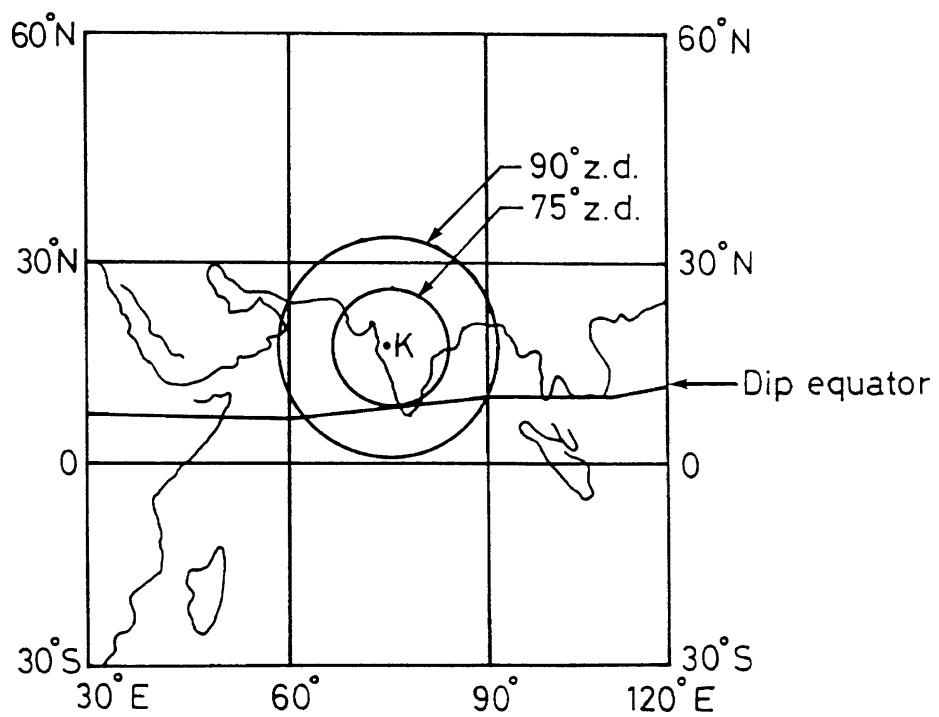

Fig. 2. The all-sky camera field of view at $75^{\circ}$ and $90^{\circ}$ zenith angles shown by two circles at $300 \mathrm{~km}$ at Kolhapur with respect to geographic coordinates. The dip equator is also indicated in the diagram. 


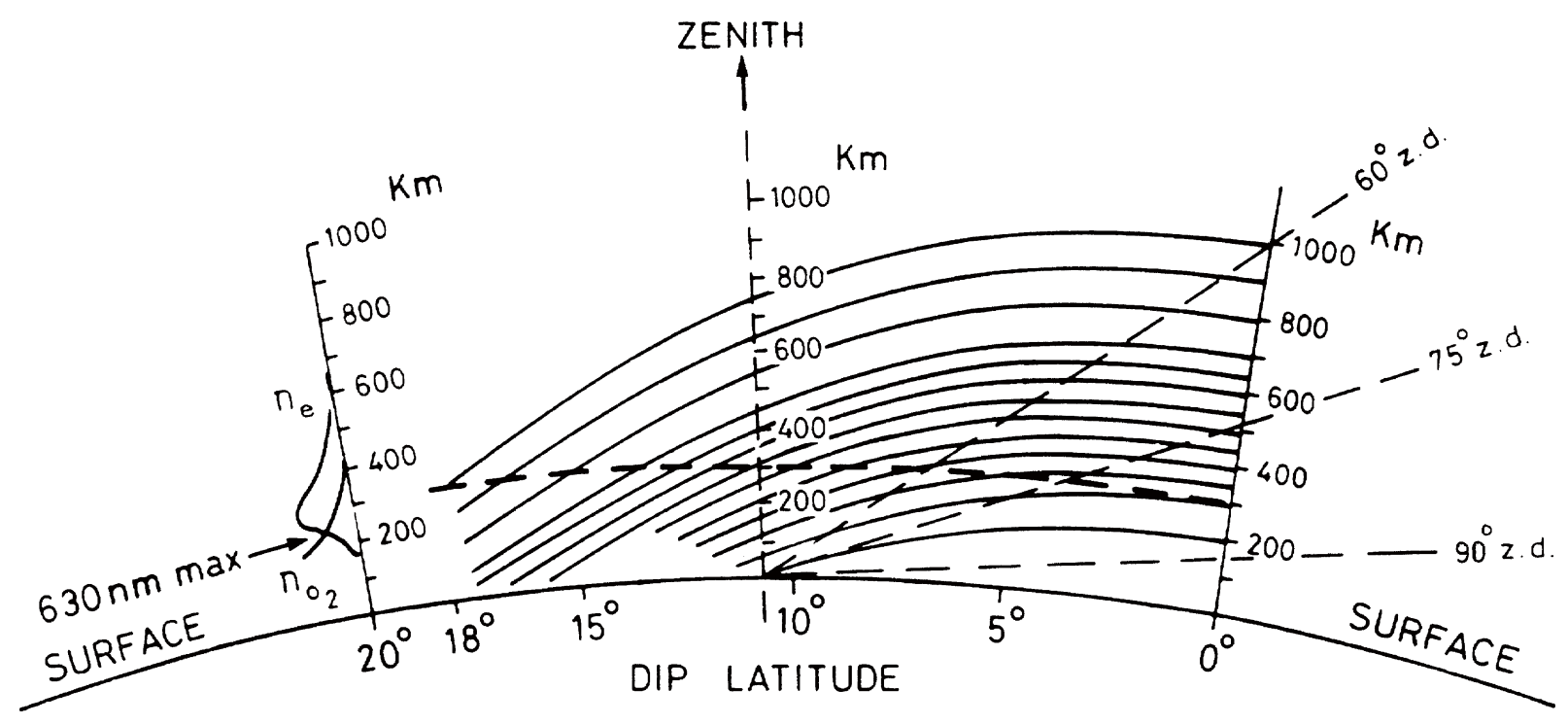

Fig. 3. Geometry of observations made in the magnetic meridian from Kolhapur $\left(10.6^{\circ} \mathrm{N}\right.$ dip lat.) of field aligned structures in the tropical ionosphere.

detector is housed in a chamber thermoelectrically cooled to $60^{\circ} \mathrm{C}$ below ambient temperature to reduce the dark signal. Very weak nightglow signals of few Rayleigh in intensity can be monitored with the system with large integration time. As the all-sky camera is not yet calibrated with a standard source, we can not give absolute values of airglow intensity. However, the intensities are classified from lowest value 0 (blue) to highest value 255 (mazenta) called the data number. The product of the data number and the constant (Rayleigh/data number) of the calibrated source would give the absolute intensity in Rayleigh. There are six filter positions which can be used to study various emission lines originating at different ionospheric heights. Since our main concern is to study $F$-region dynamics at night, we concentrate mainly on spatial and temporal characteristics of $630 \mathrm{~nm}$ emission. The spectral line at $630 \mathrm{~nm}$ is indicative of dissociative recombination involving $\mathrm{O}_{2}$ molecules and electrons near $300 \mathrm{~km}$ altitude (Mukherjee and Dyson, 1992). The superiority of charge coupled device (CCD) over almost all other image forming devices has been well established in the last two decades due to it's high resolution, high quantum efficiency, broad spectral response, low noise and large dynamic range (Janesick and Blouke, 1987; Abreu and Skinner, 1989).

\section{Geometry of Observations}

Figure 2 shows the location of the observing station Kolhapur with respect to geographic coordinates. The two circles indicate the coverage of the camera system for zenith distances $75^{\circ}$ and $90^{\circ}$ for an emission height of $300 \mathrm{~km}$. Figure 3 depicts the geometry of observations made in the magnetic meridian from Kolhapur of the field aligned structures in the tropical ionosphere. The broad band near a height of $300 \mathrm{~km}$ depicts the approximate region of $630 \mathrm{~nm}$ emission. Figure 4 shows the $75^{\circ}$ zenith angle distance at $300 \mathrm{~km}$ height which encompasses approximately $\pm 8^{\circ}$ of latitude/longitude from the zenith which is equivalent to a horizontal diameter of $\sim 1800 \mathrm{~km}$ through the zenith at 300 $\mathrm{km}$. Between zenith angles $75-90^{\circ}$, an additional $8^{\circ}$ latitude/

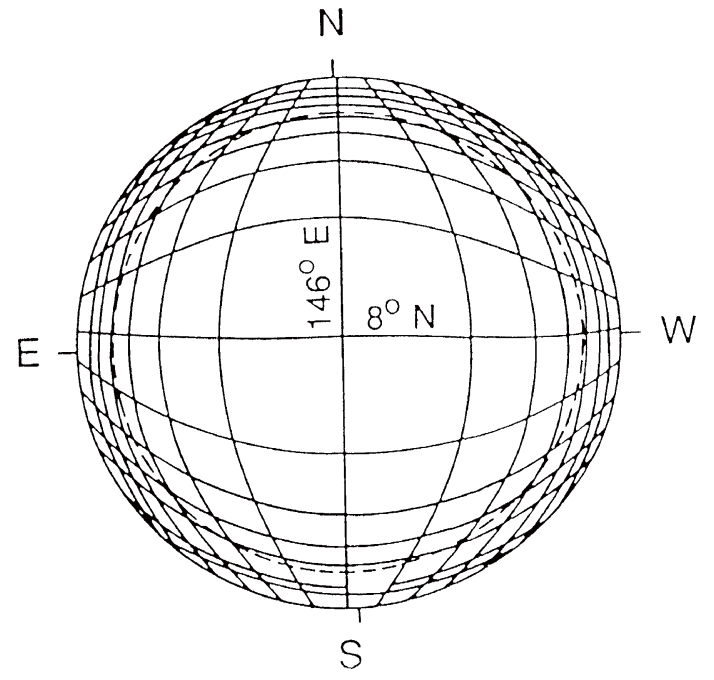

Fig. 4. Lines of magnetic latitude and longitude for $300 \mathrm{~km}$ from Kolhapur, dashed line presents a $75^{\circ}$ zenith distance.

longitude are encompassed. It is important to note, however, that the geomagnetic equator falls within $75-90^{\circ}$ zenith angles and appears near the southern edge of the field of view. To illustrate the typical nightglow images $(630 \mathrm{~nm})$ and explain $F$ region dynamics involving small and large scale irregularities we also use measurements from ionosondes, VHF scintillation and photometric experiments. We also demonstrate the thermospheric movement from west to east, north to south and from north-west to south-east direction by studying the airglow images during different times of the night. These characteristic observation features will be discussed in the following section.

\section{Observations}

In this section we present three case studies of the movement of the thermosphere and the development of equatorial ionospheric plasma depletions by OI $630.0 \mathrm{~nm}$ nightglow imaging. All the three nights (23-24 March, 
1993; 15 December, 1993 and 15 January, 1994) whose data have been presented here are magnetically quiet with moderate solar activity, the solar flux $(\mathrm{F} 10.7 \mathrm{~cm})$ ranges between 120 units on 23 March, 1993 to 83 units on 15 January, 1994.

\section{Observations on March 23-24, 1993}

All-sky images of airglow were made through $630 \mathrm{~nm}$ narrow bandwidth $(1.2 \mathrm{~nm})$ filters to produce an image every 2 minutes. It was a clear moonless night. In Fig. 5 we present a series of OI $630.0 \mathrm{~nm}$ images during the night of March 23-24, 1993 at a few minutes interval between 2346 and $0034 \mathrm{hrs}$ IST. Time is also marked in U.T. The Indian Standard Time (I.S.T.) is ahead of U.T. by five hours and thirty minutes (I.S.T. $=$ U.T. +5.5 hrs). The sequence of images after subtraction of background $(644.5 \mathrm{~nm})$ and dark current will be used to study the dynamics of the $F$-region of the ionosphere. Note the usual inversion of east-west coordinates. From north-south horizon, the region spans 3600 $\mathrm{km}$ and it shows the airglow features recorded and describe the characteristics at the base of many field lines. Note the depleted structures on the right hand side of each image. The width of the depletion varies between $50-250 \mathrm{~km}$. The north-south dimension of the structure is more than 1000 $\mathrm{km}$. The airglow intensity moves as a patch and no sharp gradient in intensity is observed within the patch. The airglow intensity within the depletion is less by two order of magnitude than the intensity in the background plasma. There appears to be a gradual change over from a single linear depleted structure to bifurcated "wishbone" structures (Mendillo and Baumgardner, 1982; Anderson and Mendillo, 1983 ) as the night progresses. The images show the appearances of second region of airglow depletion drifting to the field of view from the west.

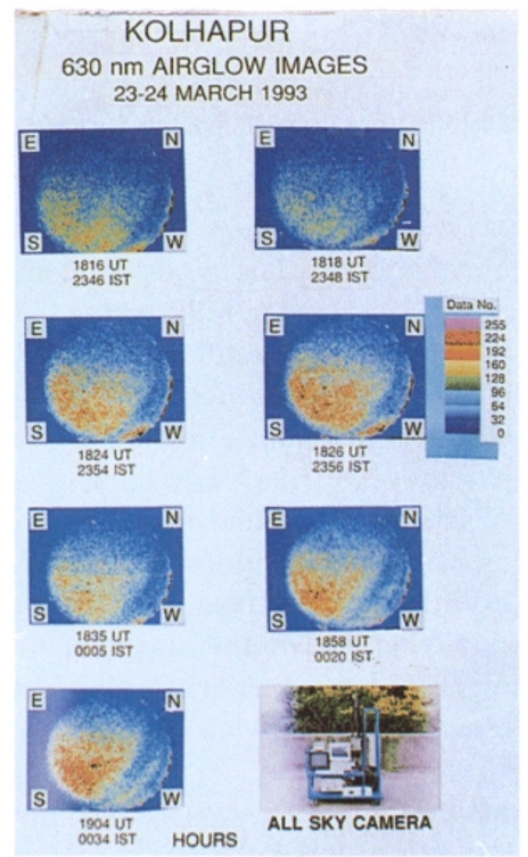

Fig. 5. All-sky images $(630.0 \mathrm{~nm})$ during the night of March 23-24, 1993 from Kolhapur. Note the moving depleted structures on the right hand side of each image.

\section{Ionosonde Observation}

Use was also made of the result of the ionospheric soundings (Model No. 1005W, Magnetic AB, Stockholm, Sweden) conducted simultaneously from the same station during the night. It was a typical spread- $F$ night. In Fig. 6, the virtual $F$-layer height $\left(h^{\prime} F\right)$ and the critical frequency $\left(f_{0} F_{2}\right)$

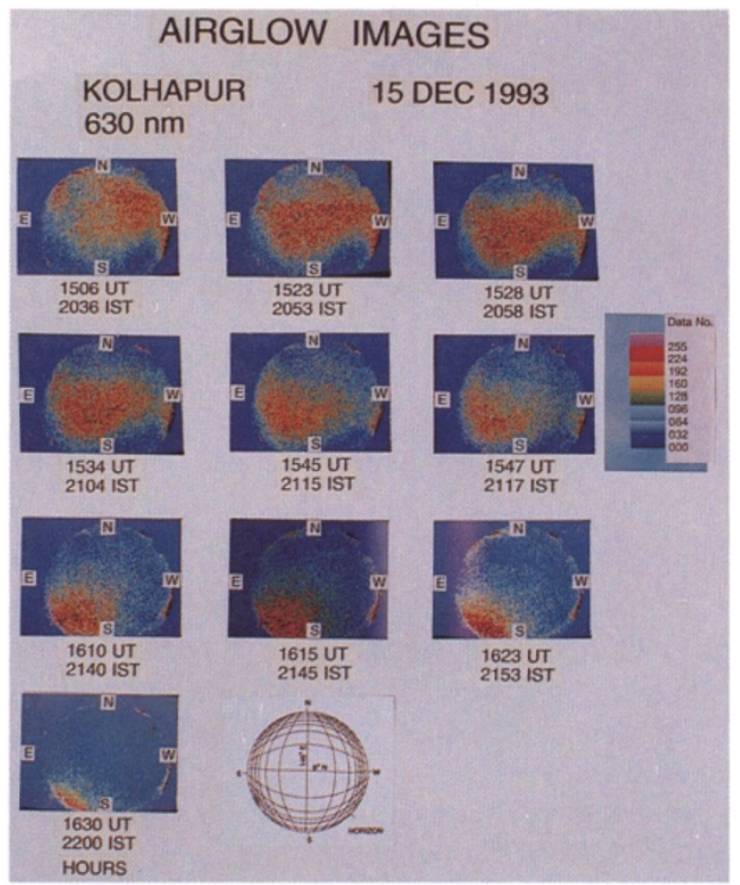

Fig. 8. The movement of the bright intensity structures in $630.0 \mathrm{~nm}$ from north-west to south-east direction on the night of December 15, 1993.

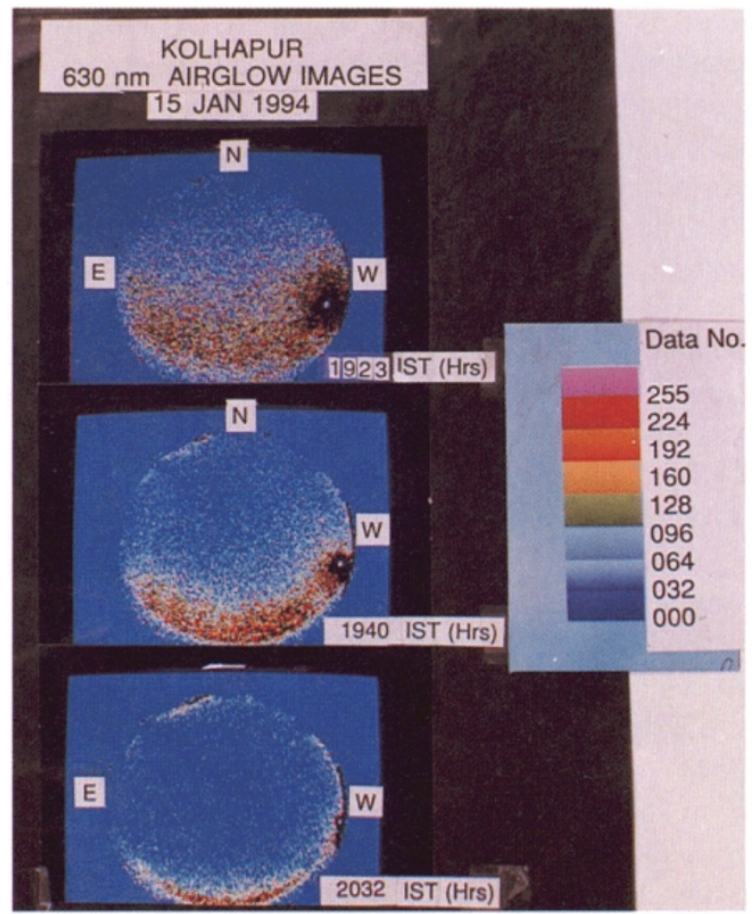

Fig. 9. The movement of the airglow features from north to south direction from all-sky images on the night of January 15, 1994. The planet on the right side of the diagram shows the setting "Moon" in the west. 
of the $F_{2}$-layer were shown as a function of time (I.S.T.) during the night of 23-24 March, 1993. Though the exact height of the layer could not be ascertained correctly due to spread- $F$ condition in the ionosphere, the lowest height during spread- $F$ condition is shown in the figure. The first ionosonde observation was made at 2045 hrs (I.S.T.) at night, the virtual height of the $F$-layer was between $350-450$ $\mathrm{km}$. Further, $N_{\max }$ (peak electron density computed from $f_{0} F_{2}$ values (Moore and Weber, 1981)) changes from $3.5 \times$ $10^{6} / \mathrm{cm}^{3}$ to $6.9 \times 10^{5} / \mathrm{cm}^{3}$ during the night. $F$-layer heights show undulations and spread- $F$ condition prevailing in the ionosphere. As the bubble (depletion in $630 \mathrm{~nm}$ ) was approaching over the station from the west to east at about 0100 hrs the layer height started ascending, simultaneously $\left(f_{0} F_{2}\right)^{2}$ values were drastically reduced. According to the theory and observations the Equatorial Spread- $F$ (ESF) season at a particular site starts when the sunset terminator aligns itself with the geomagnetic flux tube in that region, a condition typically associated for minimal thermospheric wind condition along the geomagnetic meridian (Tsunoda, 1980). It has been pointed out by Mendillo et al. (1992) that at a given longitude, the requirements for Rayleigh-Taylor (RT) instability growth within the ESF season are: (a) post sunset rise of the $F$-region, (b) the availability of a seed perturbation to launch the Rayleigh-Taylor mechanism and

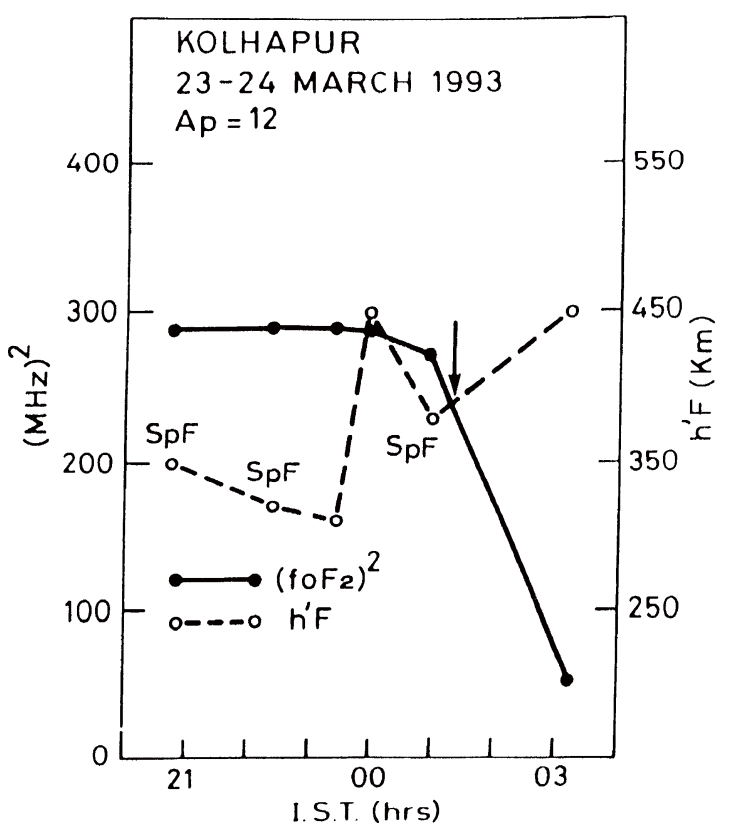

Fig. 6. The ionosonde data $N_{\max }$ (electron density at the peak of the $F_{2}$ layer) and $h^{\prime} F$ (virtual $F$-layer height) as a function of local time (I.S.T.) at Kolhapur on the night of March 23-24, 1993. Note the increase in the height of $F$-layer when the bubble moves over the station.

\section{V.H.F. SCINTILLATION RECORD AT KOLHAPUR \\ 23 - 24 MARCH 1993}
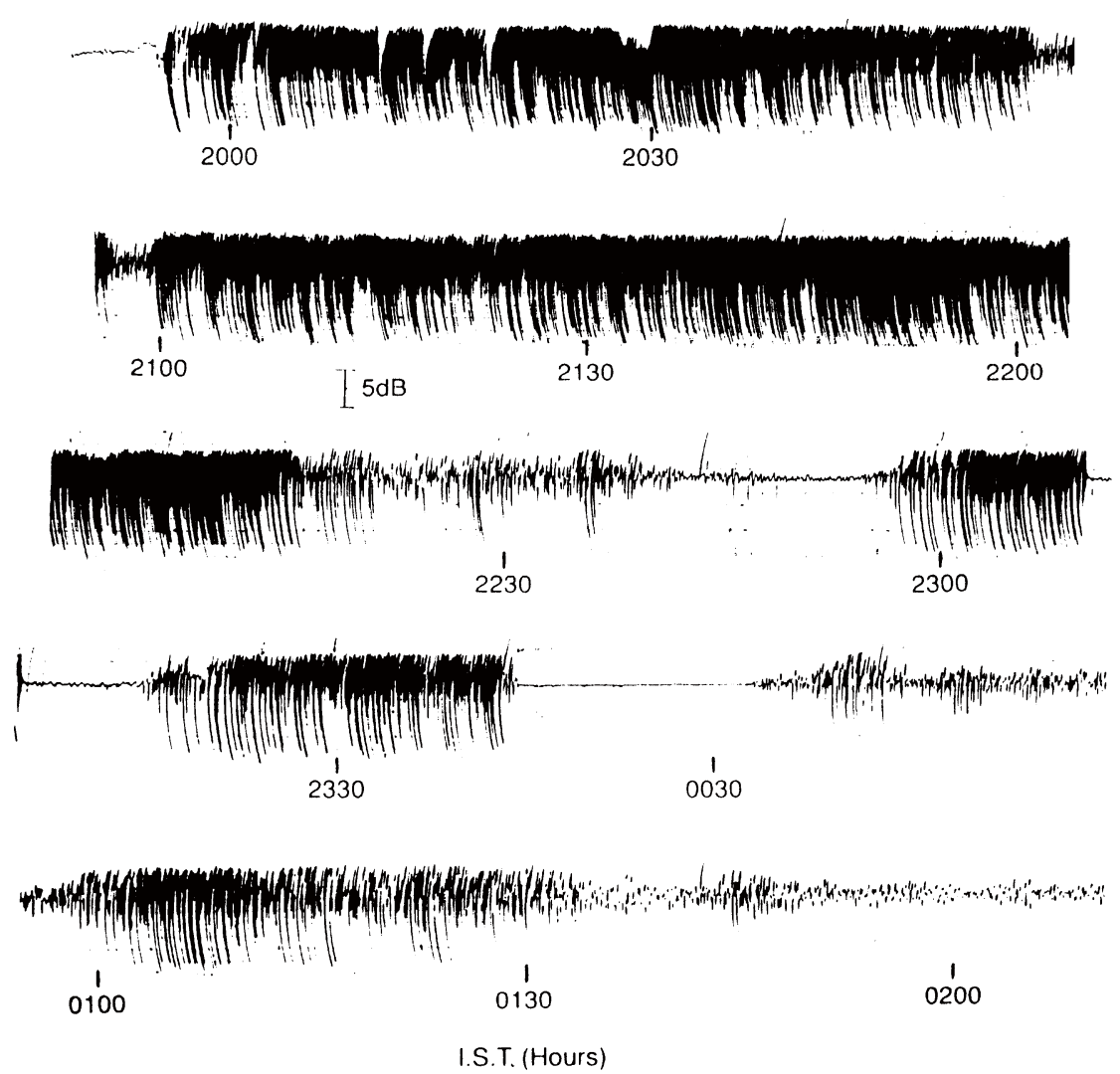

Fig. 7. The radio beacon scintillation record at $244 \mathrm{MHz}$ from the FLEETSAT $\left(72{ }^{\circ} \mathrm{E}\right)$ geo stationary satellite monitored at Kolhapur on $23-24 \mathrm{March}$, 1993. 
(c) the absence of a strong transequatorial thermospheric wind. It is generally understood that out of three controlling factors the third factor $(c)$ namely the transequatorial thermospheric wind plays the key role in suppressing or causing ESF activity at a given longitude.

\section{Scintillations Measurements}

With a view to study the small scale size irregularities within the bubbles, VHF nighttime scintillations at 244 $\mathrm{MHz}$ from the FLEETSAT geo-stationary satellite were also monitored at the station on 23-24 March, 1993. Figure 7 shows the amplitude time record of strong scintillations (>20 dB at $244 \mathrm{MHz}$ ) caused by $F$ region irregularities during the night at the time of movement of airglow depletions through the signal ray path. The time is marked on the record in Indian Standard Time (I.S.T.). The total record length has a duration of about five and half hours which is incidently the duration of observed large depletion as mapped on the all-sky imaging photograph on that night. With the passage of bubbles sudden increase in fading rate and scintillation index take place. During the interval between two bubbles the fading rate and the scintillation index are both reduced. These measurements basically signify that bottom side plasma depletion is accompanied by the $0.5-10 \mathrm{~km}$ scale size irregularities. The equatorial station, Tirunelveli $\left(8.67^{\circ} \mathrm{N}\right.$, $77.82^{\circ} \mathrm{E}$ ) showed the onset time of scintillation as $1940 \mathrm{hrs}$ (I.S.T.) which is about 15 minutes earlier. There were 4 patches recorded during the time interval of passage of the bubble at Kolhapur.

\section{Observations on December 15, 1993}

In Fig. 8 we present a sequence of the OI $630.0 \mathrm{~nm}$ images obtained on the night of December 15, 1993. This night shows the movement of airglow structures with high relative intensity from north-west to south-east direction with an apparent speed of $200 \mathrm{~m} / \mathrm{s}$. We note the movement of airglow structures was not exactly confined in east-west or north-south direction. And also the movement of the airglow structures during different time of the night was not very uniform. The sizes of the structures also keep on changing with the evolution of time. Finally they leave the field of view around 2200 hrs 1.S.T.

\section{Observations on January 15, 1994}

Figure 9 depicts the movement of bright airglow (630.0 $\mathrm{nm}$ ) structures shown by majenta colour from north to south direction. The airglow image at the top shows the appearance of bright airglow intensity regions covering $2^{\circ}$ in latitude at

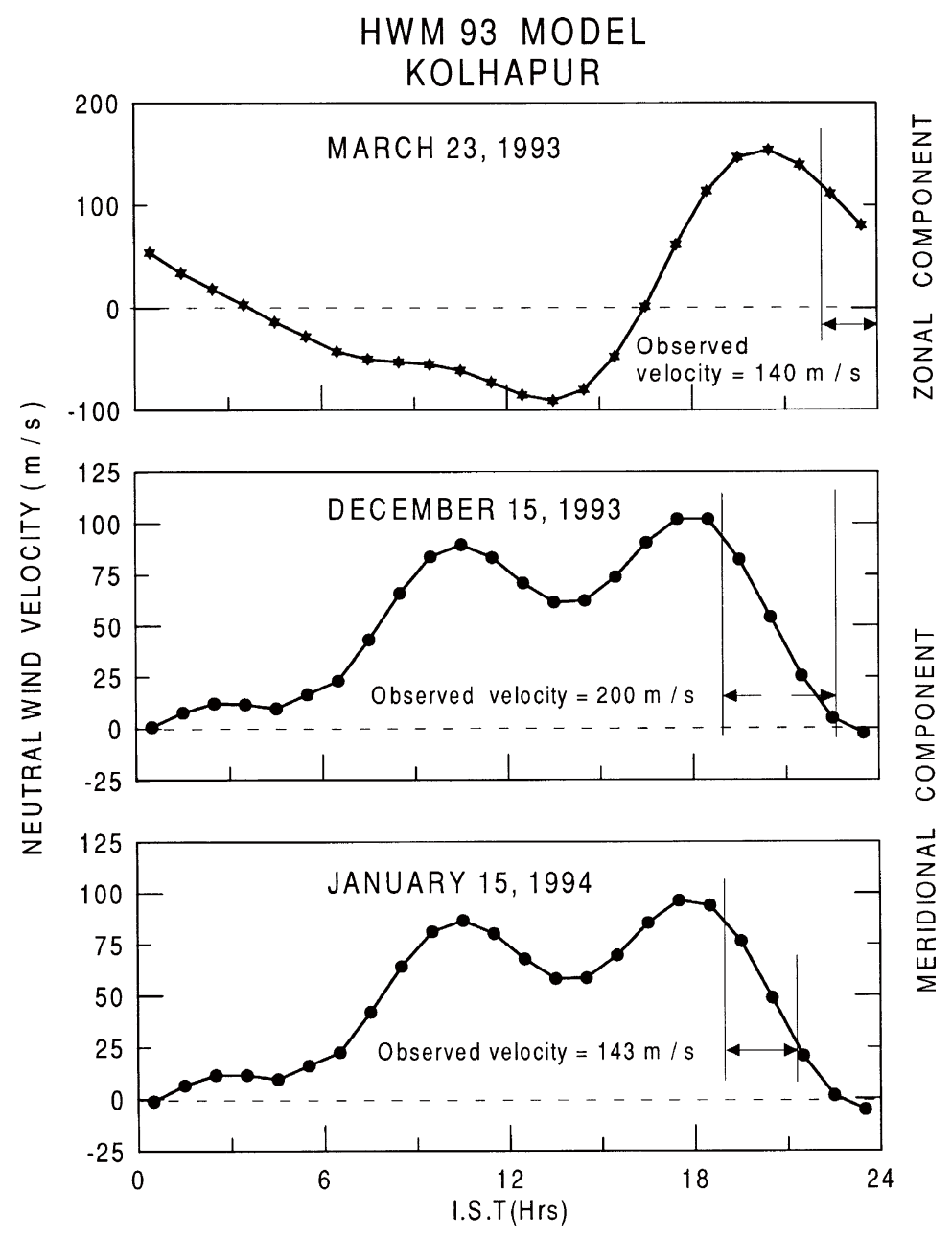

Fig. 10. The comparison of the zonal component of neutral wind velocity computed from Hedin's model (HWM93) and the eastward component of observed velocity of depletions $(630 \mathrm{~nm})$ from all-sky images on March 23, 1993 at Kolhapur (upper panel). The lower two panels show the comparison between the observed meridional velocity of airglow structures and the modelled values of meridional component of wind velocity using HWM93 model for two nights (December 15, 1993 and January 15, 1994) at Kolhapur. Note the higher observed values than their model predictions. 
the south of the station at 1923 hrs (I.S.T.) and a close examination of the well-defined features in Fig. 9 reveals that it moves totally towards the equator with an apparent drift speed of $143 \mathrm{~m} / \mathrm{s}$. Finally, the airglow structures leave the field of view around $2032 \mathrm{hrs}$ (I.S.T.). The most part of the northern portion of the sky continues to remain in low intensity and nearly at the threshold level of detection.

\section{Drifts}

Using the latitude and longitude grids (Fig. 4) of the geomagnetic field lines at $2^{\circ}$ interval for an assumed emission height of $300 \mathrm{~km}$, the eastern and western edges of the depletion were determined at different times of the night of 23-24 March, 1993. The results indicate that the depletion drifted towards east with a constant velocity of $140 \mathrm{~m} / \mathrm{s}$ during the night. On the basis of theoretical considerations it is suggested that nighttime plasma drifts near the equator are approximately equal to $F$ region neutral winds (Rishbeth, 1971; Heelis et al., 1974). Therefore, with this consideration in mind we intend to compare the observed eastward component of the bubble velocity with $F$ region neutral wind. For numerical computation of neutral wind velocity we use the Hedin's improved version (HWM93) of the model (Hedin et al., 1996) for March 23, 1993 at Kolhapur. The HWM93 model is an extension of the HWM87 and HWM90 models (Hedin et al., 1991; and references therein) including wind measurements in the thermosphere. Latitude, longitude and local time variations are suitably incorporated in the horizontal wind vector and are represented by an expansion in vector harmonics with expansion coefficient represented by a Fourier series in day of the year. The diurnal variations of the zonal component of wind velocity computed from the model are depicted in Fig. 10. The model predictions agree very well with the observations during the night. This compares well with the equatorial zonal neutral wind flow measurements by Watson instrument aboard the DE-2 satellite in 1981 as well as the ground based zonal ion drift measurement by the Jicamarca Incoherent Scatter Radar for the corresponding period (Fig. 12 in Herrero et al., 1993). The zonal plasma flow at night is found to closely coupled to zonal neutral wind as a consequence of the $F$ region dynamo. We also plot in the same figure the diurnal variation of meridional component of neutral wind velocity using HWM93 model at Kolhapur at $300 \mathrm{~km}$ altitude for 15 December, 1993 and 15 January, 1994 and compare them with available observations described earlier. The wind in the plot is positive when it moves southward. It may be noted that the largest wind velocities (both in meridional and zonal components) occur in the evening to midnight hours as the largest horizontal pressure gradients are generated in the midnight hours. The reversal occurs in the local morning hours due to building up of positive pressure gradient. The observed values of the meridional movement of the airglow structures are also shown in the figure. Note the departure of the meridional winds from the predictions. In general, the observed values are higher than the modelled estimates.

\section{Discussion and Conclusion}

In this study we have presented few examples of the thermospheric motion in north-south and east-west directions using a CCD based all-sky imaging system situated at a low latitude station, Kolhapur in India, by studying nightglow images at $630 \mathrm{~nm}$. Since our goal was to examine the signature of large scale ionospheric plasma depletions (bubbles) and smaller scale size plasma irregularities we have presented co-ordinated observations with ionosonde, radio beacon scintillation taken simultaneously during the image data set. The ionosonde provides evidence for $F$ region irregularities at the sight of observation. Additional evidence of smaller scale size irregularities is provided by radio beacon scintillation observation. The principal findings can be summarized as follows:

1) The all-sky imaging has revealed the movement of north-south (magnetic) aligned structures of airglow depletions. East-west extension of these depletions vary from 50$250 \mathrm{~km}$ with smaller structures (irregularities) as small as few $\mathrm{km}$ in size within them give rise to radio beacon scintillation. The north-south extent of these depleted plasma regions are more than $1000 \mathrm{~km}$ in length. Because of the very small magnetic declination at the observing site Kolhapur $\left(0.1^{\prime} \mathrm{W}\right)$, a clear distinction between geographic and geomagnetic alignment is not possible. The optical results for equatorial plasma bubbles presented also match closely in spatial extent and scale length to the simulation results reported by Zalesak et al. (1982) and with observations of Mendillo and Baumgardner (1982) and Weber et al. (1978, 1980).

2)On comparisons with a standard emperical model (HWM93), the observed zonal components of the plasma velocity of the bubble do match favourably well with the computed zonal component of neutral wind velocity at the station. However, there are discrepancies between observed meridional movement of the thermosphere and the model estimates. This could be due to lack of sufficient data coverage in the low latitude region of the thermosphere used to calculate the model coefficients.

Fejer et al. (1981) computed $F$ region east-west drifts at Jicamarca and obtained values of $130 \mathrm{~m} / \mathrm{s}$ during the night. The observed velocities of bubbles also compare favourably well with the earlier observations of ionospheric plasma bubbles from Brazil (Sobral et al., 1985). Yeh et al. (1979) obtained a value of eastward component of bubble as $150 \mathrm{~m} /$ s using Faraday rotation experiment and VHF scintillation measurement from a station Natal in Brazil. It seems the value of $140 \mathrm{~m} / \mathrm{s}$ is a reasonable estimate of velocity of the eastward component of the plasma bubble at the given low latitude observing site. Though the observation was carried out during low solar activity period in summer equinoctial night (March 23-24, 1993), the results do not portray any marked latitudinal gradient in bubble zonal velocity as was reported by Sobral et al. (1990) and Abdu et al. (1987) using two $630 \mathrm{~nm}$ scanning photometers over Cachoeira Paulista $\left(22.6^{\circ} \mathrm{S}, 45^{\circ} \mathrm{W}\right)$. Bittencourt et al. (1997) presented the first simultaneous ionospheric, thermospheric and airglow observations in the Brazilian low-latitude region, to study the generation and evolution of large-scale ionospheric plasma depletions. Their observations support the present views of equatorial plasma generation mechanism which include a rapid post-sunset lifting of the equatorial $F$-layer and the presence of a "seed perturbation" to generate the Rayleigh- 
Taylor instability in the evening equatorial $F$-layer. The spread- $F$ condition was prevailing in the $F$ region of the ionosphere and the thermospheric motion was confined in the east-west direction with practically no movement in meridional direction. This is perhaps the ideal condition of generating Spread- $F$ irregularities in the post sunset hours when the sunset terminator aligns itself along the geomagenetic meridian and the result agrees well with the theoretical model proposed by Tsunoda (1980). Further detailed comparisons of the apex altitude of the plasma depleted flux tubes which are not reported here will be made with the similar characteristic observations reported by Mendillo and Tyler (1983) in the American sector and more recently by Sahai et al. (1996) in Brazilian sector.

Acknowledgments. The all-sky camera has been developed with the collaboration of Prof. M. Mendillo and his group at Boston University, Boston, U.S.A. One of the authors (G.K.M.) would like to thank Prof. M. Mendillo and Boston University, U.S.A., for their kind hospitality during a visit to Boston University. Many useful discussions with Prof. M. Mendillo, Mr. J. Baumgardner and Mr. D. Nottingham during the course of this work are gratefully acknowledged. The authors are grateful to Prof. R. V. Bhonsle, Department of Physics, Shivaji University, Kolhapur, India, for providing the ionosonde data. The scintillation experiment at Kolhapur is conducted under the joint collaboration between IIG, Mumbai and Shivaji University, Kolhapur. The research in Upper Atmospheric Science in IIG is funded by Department of Science and Technology (DST), Government of India,New Delhi.

The Editor thanks N. Iwagami and S. Okano for their kind help in evaluating this paper.

\section{References}

Abdu, M. A., J. H. A. Sobral, Y. Nakamura, and C. J. Zamlutti, Equatorial plasma bubble zonal velocity height gradient from spaced VHF polarimeter and scanning $630 \mathrm{~nm}$ measurements, Geophys. Res. Lett., 14, 965-967, 1987.

Abreu, V. J. and W. R. Skinner, Inversion of Fabry-Perot CCD images: Application to doppler shift measurements, Appl. Opt., 28, 3382-3388, 1989.

Anderson, D. N. and M. Mendillo, Ionospheric conditions affecting the evolution of equatorial plasma depletions, Geophys. Res. Lett., 10, 541544, 1983.

Baumgardner, J. and S. Karandanis, CCD system using video graphics controller, Electronic Imaging, 3, 28-31, 1984.

Bittencourt, J. A., Y. Sahai, P. R. Fugundes, and H. Takahashi, Simultaneous observations of equatorial $F$-region plasma depletions and the thermospheric winds, J. Atmos. Terr. Phys., 59(9), 1049-1059, 1997.

Carman, E. H., Equatorial depletions in the $630.0 \mathrm{~nm}$ airglow at Vanimo, Planet. Space Sci., 31, 355-362, 1983.

Dyson, P. L. and R. F. Benson, Topside sounder observations of equatorial bubbles, Geophys. Res. Lett., 5, 795-798, 1978.

Fejer, B. G., D. T. Farley, C. A. Gonzales, R. F. Woodman, and C. Calderon, $F$ region east-west drifts at Jicamarca, J. Geophys. Res., $\mathbf{8 6}$, 215-218, 1981.

Fukunishi, H., Report on ionosphere-thermosphere coupling and response to energy and momentum inputs, in Solar Terrestrial Environmental Research in Japan, Committee on Solar-Terrestrial Environment Research, Nagoya University, Japan, 18, 21-23, 1996.

Hake, Jr., Studies of the motion of equatorial $630.0 \mathrm{~nm}$ airglow depletions, Planet. Space Sci., 29, 1267-1272, 1981.

Hedin, A. E., M. A. Biondi, R. G. Burnside, G. Hernandez, R. M. Johnson, T. L. Killeen, C. Mazaudier, J. W. Meriwether, J. E. Salah, R. J. Sica, R. W. Smith, N. W. Spencer, V. B. Wickwar, and T. S. Virdi, Revised global model of thermosphere winds using satellite and ground based observations, J. Geophys. Res., 96, 7657-7688, 1991.

Hedin, A. E., E. L. Fleming, A. H. Manson, F. J. Schmidin, S. K. Avery, R. R. Clark, S. J. Franke, G. J. Fraser, T. Tsuda, F. Vial, and R. A. Vincent, Emperical wind model for the upper, middle and lower atmosphere, J. Atmos. Terr. Phys., 58(13), 1421-1427, 1996.

Heelis, R. A., P. C. Kendall, R. J. Moffett, D. W. Windle, and H. Rishbeth, Electric Coupling of the $E$ - and $F$-regions and it's effect of $F$ region drifts and winds, Planet. Space Sci., 22, 743-756, 1974.

Herrero, F. A., N. W. Spencer, and H. G. Mayr, Thermosphere and $F$-region plasma dynamics in the equatorial region, Adv. Space Res., 13(1), 201220, 1993.

Janesick, J. and M. Blouke, Sky on a chip: The fabulous CCD, Sky and Telescope, 9, 238-242, 1987.

Malcolm, R., C. Miles, and B. A. Tinsley, Field aligned observations of trans-equatorial bubbles from Rarotonga in 1969-1970, Geophys. Res. Lett., 11, 665-668, 1984.

McClure, J. P., W. B. Hanson, and J. H. Hoffman, Plasma bubbles and irregularities in the equatorial ionosphere, J. Geophys. Res., 82, 26502656, 1977.

Mendillo, M. and J. Baumgardner, Airglow characteristics of equatorial plasma depletions, J. Geophys. Res., 87, 7641-7652, 1982.

Mendillo, M. and A. Tyler, Geometry of depleted plasma regions in the equatorial ionosphere, J. Geophys. Res., 88, 5778-5782, 1983.

Mendillo, M., J. Baumgardner, and P. J. Sultan, Optical and radar techniques applied to chemical release in active experiments in the ionosphere/thermosphere system, Adv. Space Res., 10, 8-15, 1989.

Mendillo, M., J. Baumgardner, X.-Q. Pi, P. J. Sultan, and R. T. Tsunoda, Onset conditions for equatorial spread-F, J. Geophys. Res., 97, 1386513876, 1992

Moore, J. G. and E. J. Weber, OI 6300 and $7774 \AA$ A airglow measurements of equatorial plasma depletions, J. Atmos. Terr. Phys., 43, 851-858, 1981.

Mukherjee, G. K. and P. L. Dyson, A filter tilting photometer for nightglow measurement of $630.0 \mathrm{~nm}$ emission line, Ind. J. Radio Space Phys., 21, 212-217, 1992.

Mukherjee, G. K., L. Carlo, and P. T. Patil, First all-sky imaging observations from India, South Pacific STEP workshop, New Castle, Australia, July 3-9, 1993.

Mukherjee, G. K., L. Carlo, and P. T. Patil, All-sky imaging observations from low latitudes, in Proc. Saha Memorial Symposium on Science and Technology (Plasma93), edited by I. M. L. Das, pp. 219-222, Allied Publishers, New Delhi (India), 1994.

Muldrew, D. B., Characteristics of ionospheric bubbles determined from aspect sensitive scatter spread-F observed with Alouette 1., J. Geophys. Res., 85, 2115-2123, 1980.

Rishbeth, H., The F-layer dynamo, Planet. Space Sci., 19, 263-267, 1971. Rohrbaugh, R. P., W. B. Hansen, B. A. Tinsley, B. L. Cragin, J. P. McClure, and A. L. Broadfoot, Images of transequatorial bubbles based on field-aligned airglow observations from Haleakala in 19841986, J. Geophys. Res., 94, 6763-6770, 1989.

Sahai, Y., J. A. Bittencourt, N. R. Teixeira, and H. Takahashi, Plasma irregularities in the tropical $F$-region detected by OI $7774 \AA$ and 6300 Å nightglow measurements, J. Geophys. Res., 86, 3496-3500, 1981.

Sahai, Y., J. Aarons, M. Mendillo, J. Baumgardner, J. A. Bittencourt, and H. Takahashi, OI $630 \mathrm{~nm}$ imaging observations of equatorial plasma depletions at $16^{\circ} \mathrm{S}$ dip latitude, J. Atmos. Terr. Phys., 56, 1461-1475, 1994.

Sahai, Y., J. A. Bittencourt, J. H. A. Sobral, P. R. Fagundes, and H. Takahashi, Observations of ionospheric plasma depletions using OI 630.0 nm nightglow imaging, Revista Bras de Geophys, 14(1), 15-28, 1996.

Sinha, H. S. S., R. N. Misra, H. Chandra, Sikha Raizada, N. Dutta, and G. D. Vyas, Multiple-wavelength optical imaging of ionospheric plasma depletions, Ind. J. Radio Space Phys., 25, 44-52, 1996.

Sobral, J. H. A., M. A. Abdu, and Y. Sahai, Equatorial plasma bubble eastward velocity characteristics from scanning airglow photometer measurements over Cachoeira Paulista, J. Atmos. Terr. Phys., 47, 895900, 1985.

Sobral, J. H. A., M. A. Abdu, and Y. Sahai, Latitudinal gradient in the plasma zonal velocities as observed by scanning 630-nm airglow measurements, J. Geophys. Res., 95, 8253-8257, 1990.

Tinsley, B. A., Field aligned airglow observations of trans-equatorial 
bubbles in the tropical F-region, J. Atmos. Terr. Phys., 44, 547-557, 1982.

Tsunoda, R. T., On the spatial relationship of 1-m equatorial spread $F$ irregularities and plasma bubbles, J. Geophys. Res., 85, 185-190, 1980.

Weber, E. J., J. Buchau, R. H. Eather, and S. B. Mende, North-south aligned equatorial airglow depletions, J. Geophys. Res., 83, 712-716, 1978.

Weber, E. J., J. Buchau, and J. G. Moore, Airborne studies of equatorial F-layer ionospheric irregularities, J. Geophys. Res., 85, 4631-4641, 1980

Weber, E. J., H. C. Brinton, J. Buchau, and J. G. Moore, Coordinated airborne and satellite measurements of equatorial plasma depletions, $J$ Geophys. Res., 87, 10503-10513, 1982.

Weber, E. J., J. Aarons, and A. L. Johnson, Conjugate studies of an isolated equatorial irregularity region, J. Geophys. Res., 88, 3175-3180,
1983

Woodman, R. F. and C. La Hoz, Radar observations of $F$ region equatorial irregularities, J. Geophys. Res., 81, 5447-5466, 1976.

Yeh, K. C., H. Soicher, C. H. Liu, and E. Bonelli, Ionospheric bubbles observed by the Faraday rotation method at Natal, Brazil, Geophys. Res. Lett., 6, 473-475, 1979.

Zalesak, S. T. and S. L. Ossakow, Mem. Repl. 4899, Naval Res. Lab., Washington, D.C., 1982.

Zalesak, S. T., S. L. Ossakow, and P. K. Chaturvedi, Nonlinear equatorial spread $F$ : The effect of neutral winds and background Pederson conductivity, J. Geophys. Res., 87, 151-155, 1982.

G. K. Mukherjee (e-mail: gkm@iig.iigm.res.in), L. Carlo, S. H. Mahajan, and P. T. Patil 